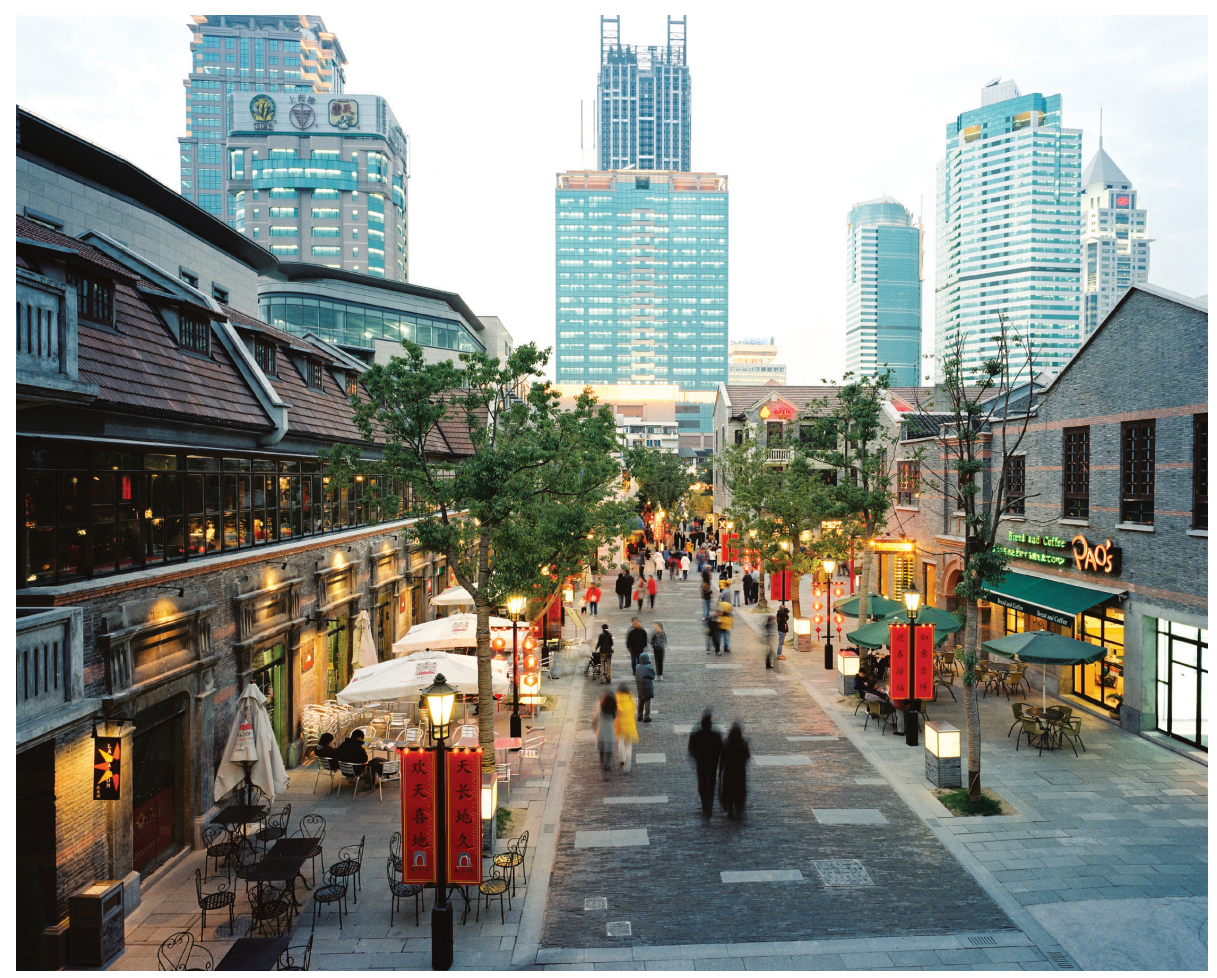

Plate 1 Xintiandi, developed by Shui On Land and designed by Wood and Zapata; Skidmore, Owings, and Merrill; and Nikken Sekkei International, built 1997-2002. Image courtesy of Benjamin Wood Studio. 


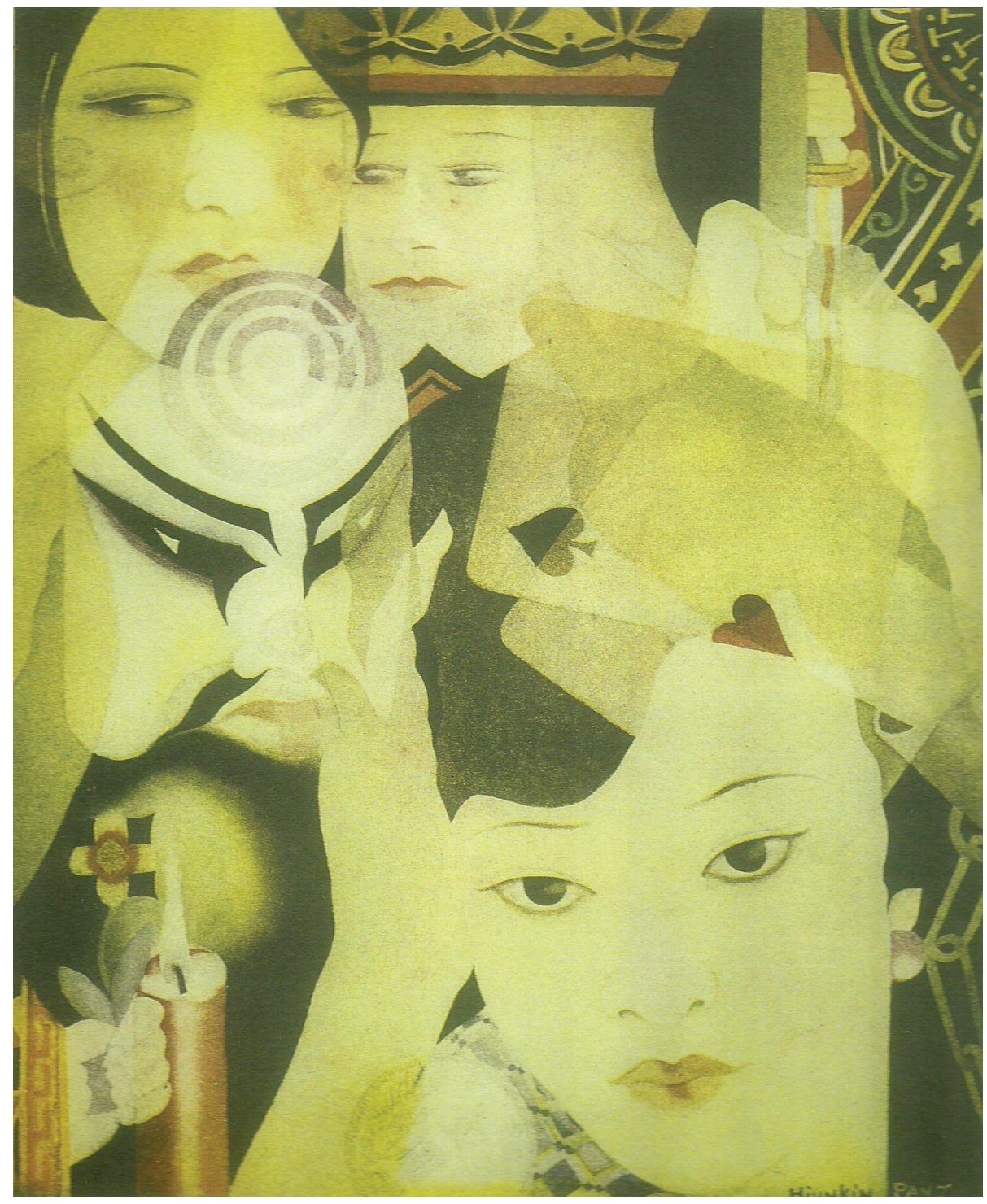

Plate 2 Pang Xunqin, Such is Shanghai, or The Riddle of Life, 1931. Watercolor on paper. Destroyed. Image courtesy of Changshu Art Museum. 


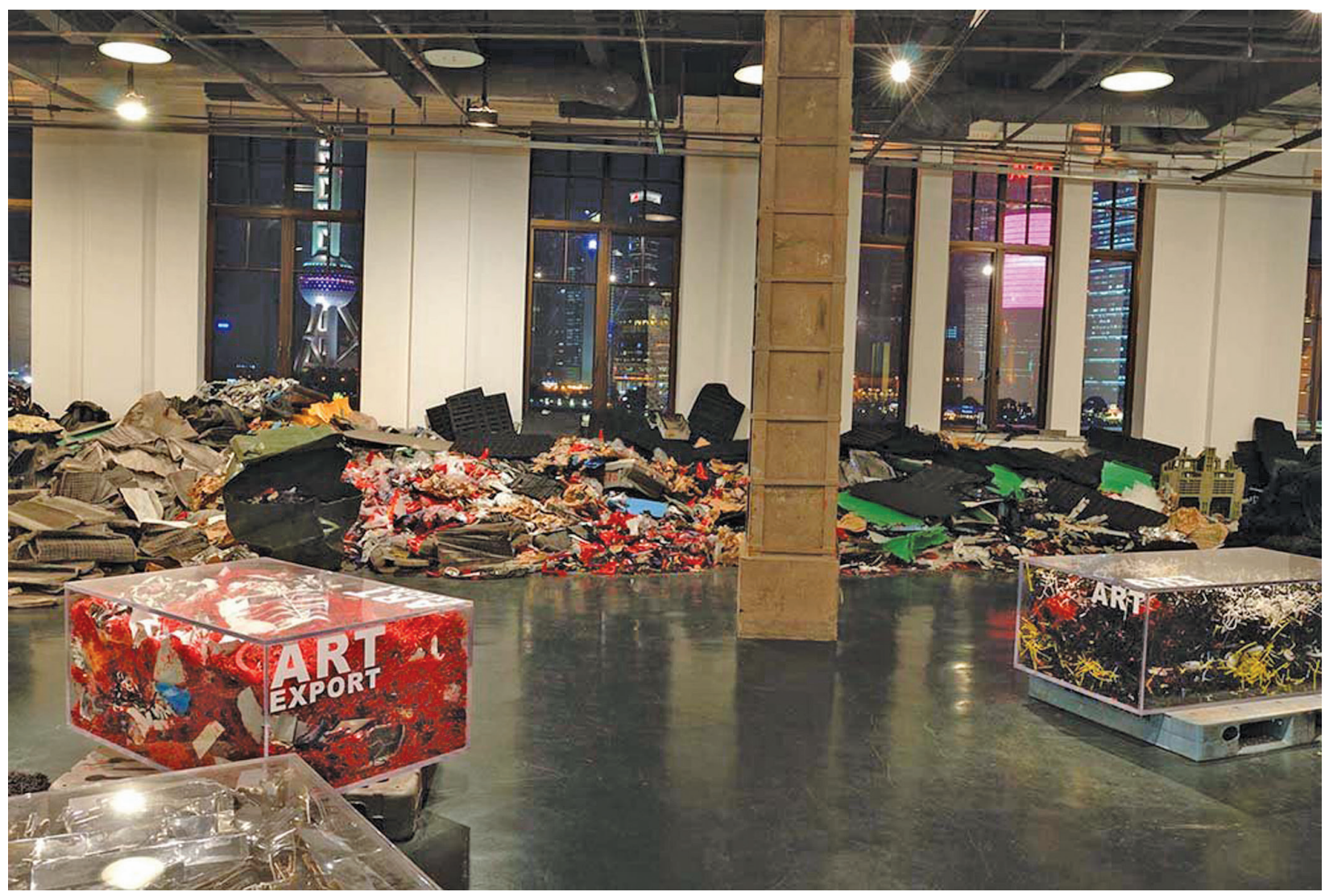

Plate 3 Liu Jianhua, Export_Cargo Transit, 2007. Installation view at Shanghai Gallery of Art, Shanghai, China. Image courtesy of artist. 


\section{The First Intellectual The First Intellectual The First Intellectual}

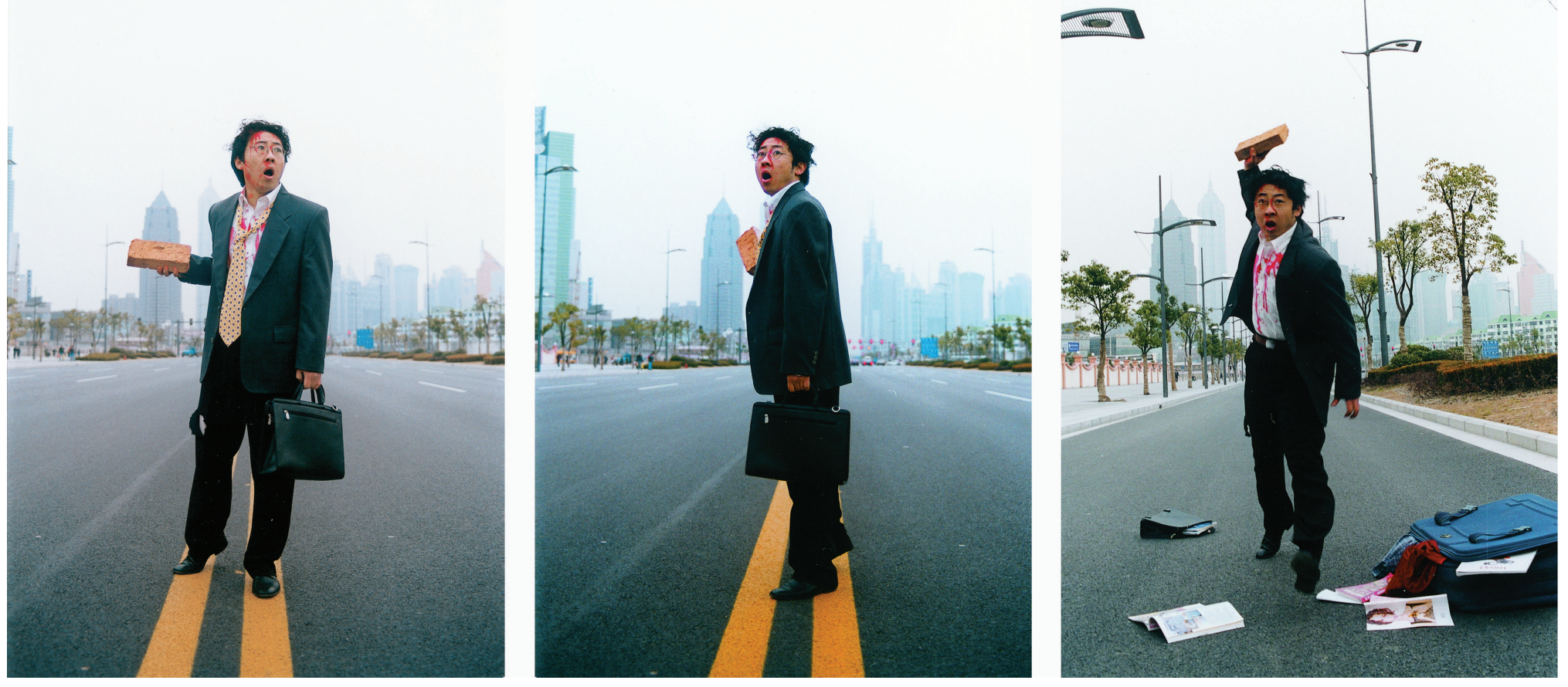

Plate 4 Yang Fudong, The First Intellectual, 2000. 3 color photographs. $76 \times 50$ inches each. Images courtesy of artist and Marian Goodman Gallery. 

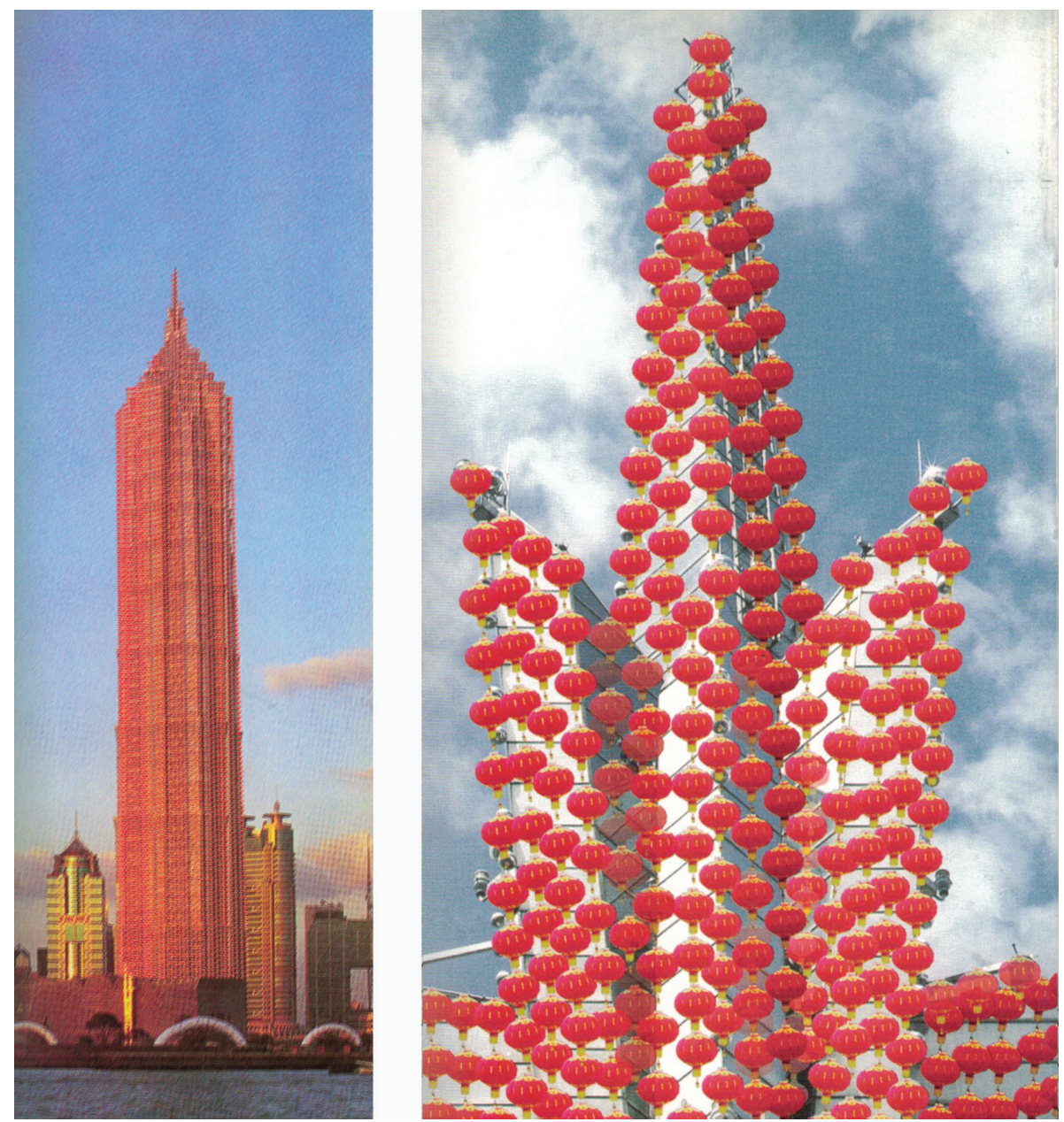

Plate 5 Gu Wenda, Heavenly Lantern Project for Shanghai's Jin Mao Tower, 2003. Proposed project renderings. Images courtesy of artist. 


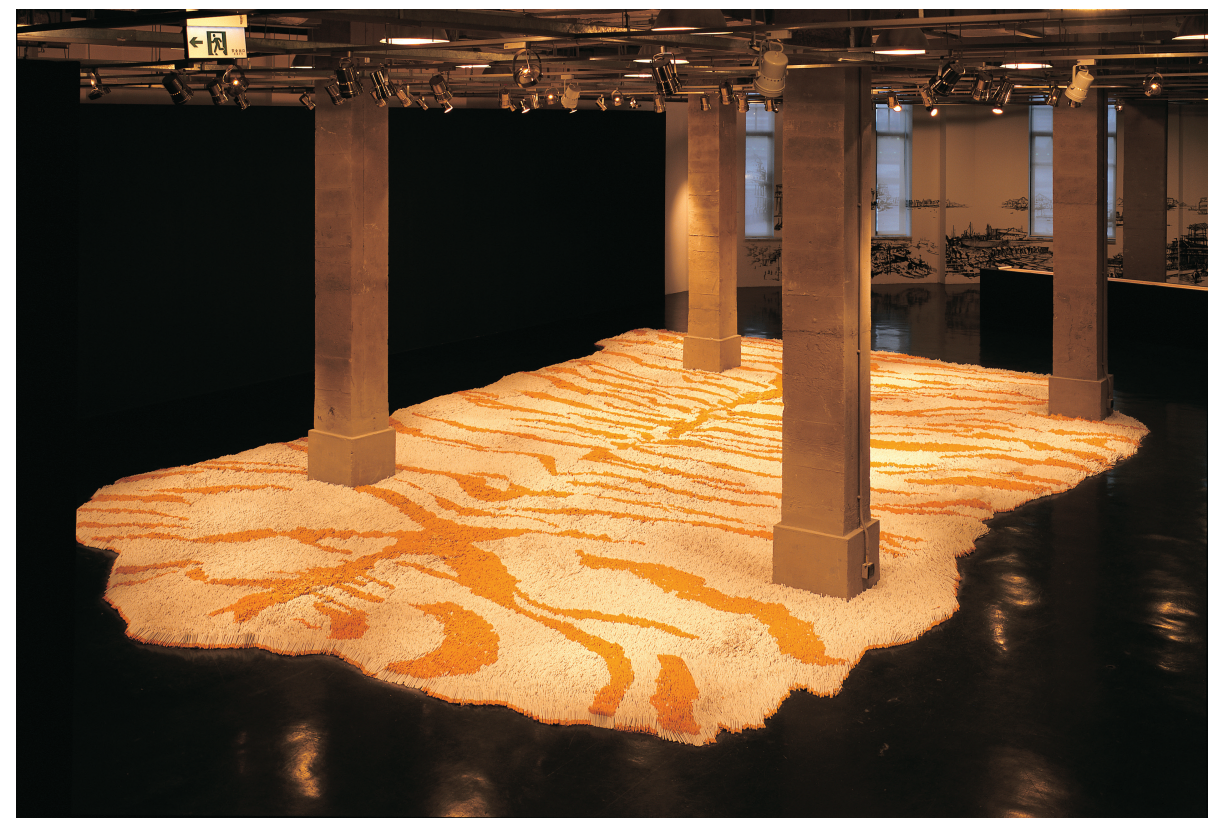

Plate 6 (a) Xu Bing, Honor and Splendor (Shanghai Version), 2004. 660,000 "Wealth" brand cigarettes, spray adhesive, cardboard. Approx. $354 \times 275$ inches. Installation view at Shanghai Gallery of Art, Shanghai, China, 2004. @ Xu Bing Studio.

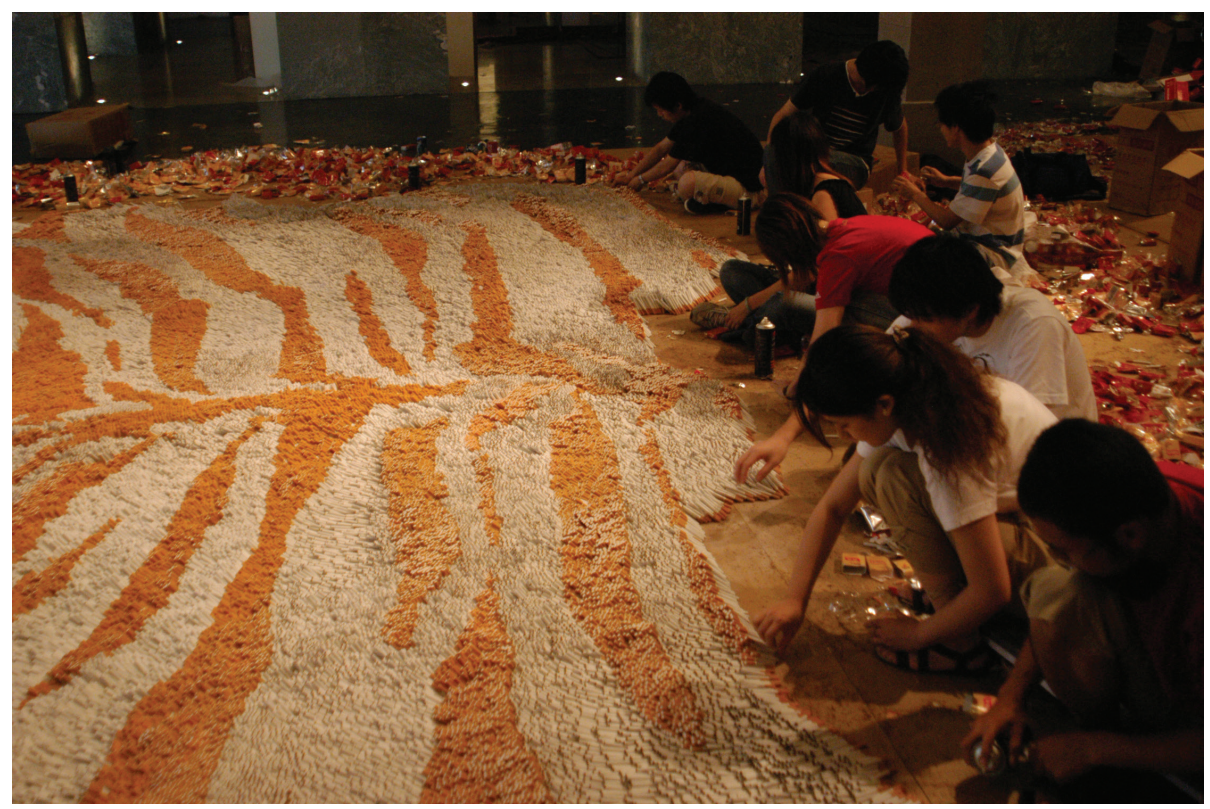

Plate 6 (b) Xu Bing, Honor and Splendor (Shanghai Version), 2004. 660,000 "Wealth" brand cigarettes, spray adhesive, cardboard. Approx. $354 \times 275$ inches. View of assistants assembling cigarettes at Shanghai Gallery of Art, Shanghai, China, 2004. ๑ Xu Bing Studio. Images courtesy of artist. 

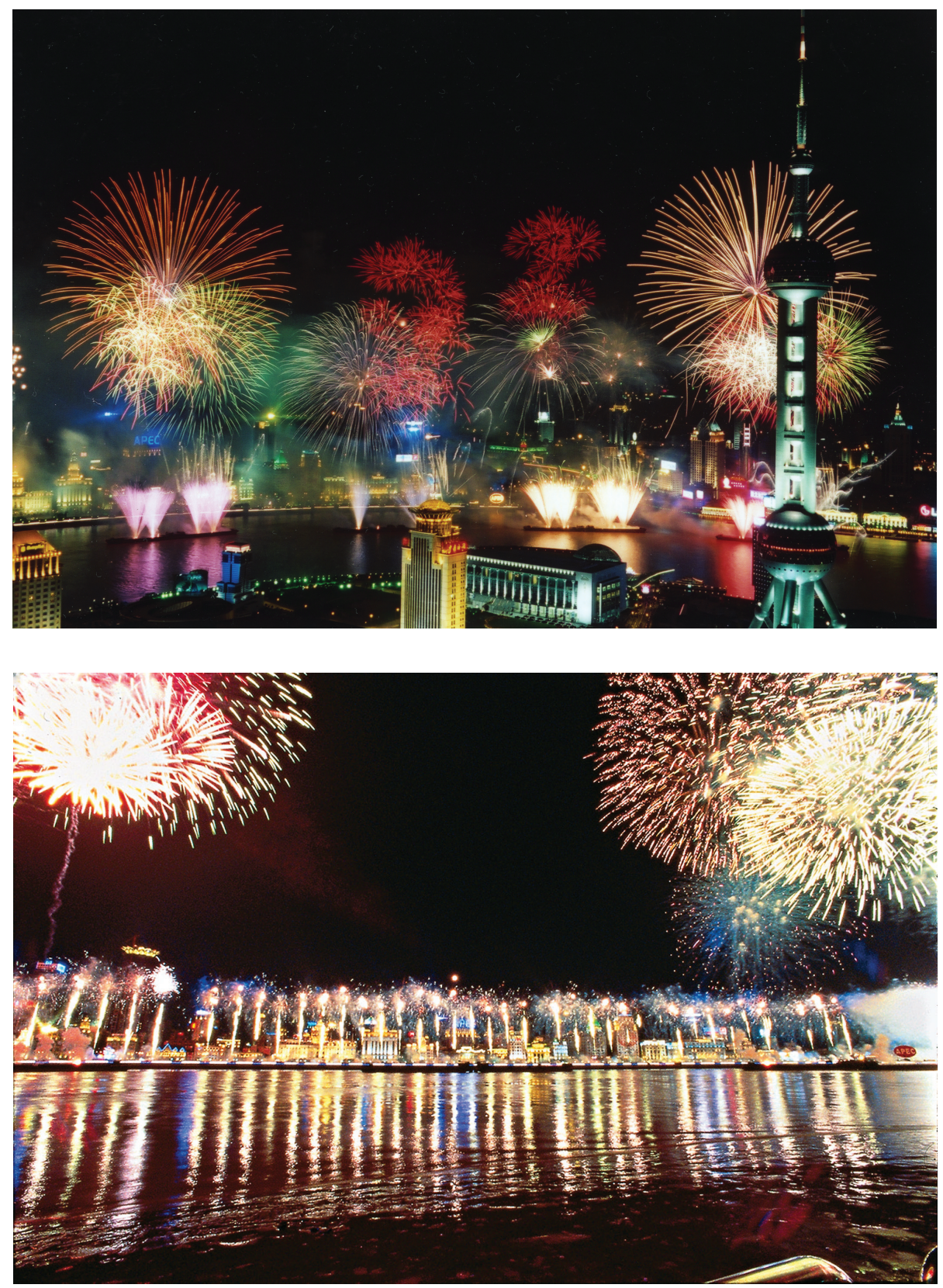

Plate 7 Cai Guo-Qiang, Asia-Pacific Economic Cooperation (APEC) Cityscape Fireworks, realized at the Bund, Lujiazui, and Huangpu River, Shanghai, China, on October 20, 2001. Images courtesy Cai Studio. 


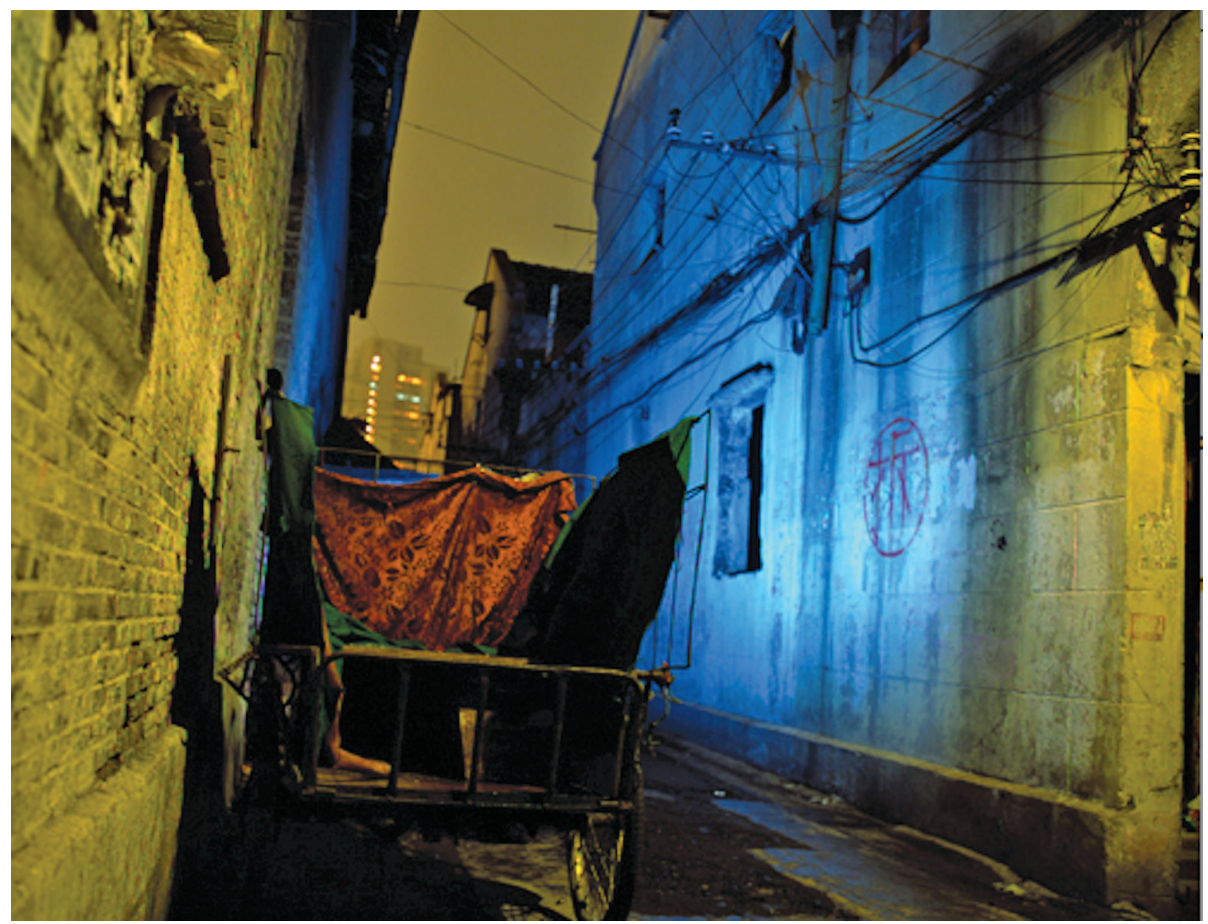

Plate 8 Liu Jiajia, Pedicab in an old longtang alley, from series The Forgotten Corner of the City was Quiet at Last, 2006. Color photograph. (This photograph was taken in a neighborhood slated for demolition, apparent in the wall marking: 拆/chai.) Image courtesy of artist. 